\title{
A CRÔNICA E A CASA ASSASSINADA: O DISCURSO DA FEMINILIDADE FREUDIANA EM LÚCIO CARDOSO
}

\section{${ }^{*}$ Alaiana Menezes da Silva, ${ }^{2}$ Ana Carolina Peck Vasconcelos, ${ }^{3}$ Daniele Evelin Viana Pinheiro, ${ }^{4}$ Jessica Samantha Lira da Costa, 5 Julliana Morgado Rocha and ${ }^{6}$ Tamires Viana}

${ }^{1}$ Mestra em Psicologia (UFPA), Especialista em Saúde da Mulher e da Criança (UFPA); ${ }^{2}$ Psicóloga. Especialista Em Psicologia Hospitalar, Mestra em Psicologia (UFPA), Docente e Coordenadora de Clínica da Unama; ${ }^{3}$ Psicanalista (NIPSAM), Diretora e Coordenadora do Centro de Estudos Freudianos de Belém; ${ }^{4}$ Mestra e Doutoranda em Psicanálise - teoria e clínica (UFPA), Docente e Coordenadora Adjunta do curso de Psicologia da

Estácio - Nazaré (BELÉM); ${ }^{5}$ Psicóloga, Mestra e Doutoranda em Cuidados Paliativos (Universidade do Porto), Atualmente é coordenadora de ensino e extensão da APAE BELÉM; 6Psicóloga (UNAMA), Mestranda em

Psicologia na Universidade de São Paulo (USP), Psicóloga hospitalar no Albert Einstein (SP)

\section{ARTICLE INFO}

\section{Article History:}

Received $11^{\text {th }}$ February, 2021

Received in revised form

$26^{\text {th }}$ March, 2021

Accepted $08^{\text {th }}$ April, 2021

Published online $22^{\text {th }}$ May, 2021

\section{Key Words:}

Cuidados Paliativos; Unidade de Terapia

Intensiva; Teoria de Enfermagem; Cuidado

Paliativos na Terminalidade da Vida;

Técnicos de Enfermagem.

\section{*Corresponding author:}

Alaiana Menezes da Silva

\begin{abstract}
O presente artigo tem por objetivo realizar uma leitura com base na perspectiva psicanalítica, centrada na Teoria da Feminilidade de Sigmund Freud, do longa-metragem A casa assassinada (1971), dirigido pelo cineasta Paulo César Saraceni, uma vez que este é baseado no romance de Lúcio Cardoso, Crônica da casa assassinada (1959). A análise busca a elucidação da personagem Nina, tendo em vista que esta ocupa lugar central na narrativa e apresenta traços que corroboram para a teoria freudiana. Posteriormente, será esboçada uma breve relação entre cinema e psicanálise, no que diz respeito a interlocução entre ambos na área de estudos psicanalíticos. No entanto, antes de fazermos esta relação entre cinema e psicanálise, em diálogo com o romance Crônica da casa assassinada, desenvolveremos uma breve análise de dois pontos que consideramos ser determinantes para que, de fato, ocorra o processo de feminilidade na narrativa: os múltiplos pontos de vista dos narradores e, principalmente, o alto grau de representatividade no romance. Também, abordaremos como ocorrera o processo de evolução estilística na composição literária cardosiana até que o autor chegasse a produção de sua obraprima Crônica da casa assassinada.
\end{abstract}

Copyright (C) 2021, Alaiana Menezes da Silva et al. This is an open access article distributed under the Creative Commons Attribution License, which permits unrestricted use, distribution, and reproduction in any medium, provided the original work is properly cited.

Citation: Alaiana Menezes da Silva, Ana Carolina Peck Vasconcelos, Daniele Evelin Viana Pinheiro, Jessica Samantha Lira da Costa, Julliana Morgado Rocha and Tamires Viana, 2021. "A crônica e a casa assassinada: o discurso da feminilidade freudiana em lúcio cardoso", International Journal of Development Research, 11, (05), 47063-47067.

\section{INTRODUÇÃO}

\section{A Crônica da casa Assassinada}

Construindo Uma Revolução : A produção artística de Lúcio Cardoso (1912-1968) é marcada pela multiplicidade. Polígrafo, cultivou tanto a novela e o romance quanto a poesia, o jornalista fez crítica literária, conto e crônica, o homem do teatro ousou lançar-se ao cinema, escondendo o artista plástico que só se realizou após a hemiplegia de 1962. Entretanto, seu reconhecimento como escritor dá-se, principalmente, por sua produção romanesca e, em especial, por sua obra-prima, Crônica da casa assassinada (1959). De acordo com Mario Carelli (1951-1994), historiador e sociólogo francês, biografo e estudioso da obra cardosiana, que examina, em Cordel de fogo (1988), as diversas manifestações artísticas do escritor mineiro, a produção escrita de Lúcio Cardoso caminha em uma evolução que culmina na publicação da Crônica. Detendo-nos à produção romanesca, é possível afirmar, então, que todos os romances anteriores ao romance de 1959, isto é, Maleita (1934), Salgueiro (1935), A luz no subsolo (1936) e Dias perdidos (1943), antecipam características e técnicas narrativas que reaparecem, de forma ímpar, no romance que o consagrou. Segundo Carelli (1988) Maleita, que embora não seja perfeitamente realizado já é um romance plenamente cardosiano e apresenta características bem marcantes em Crônica da casa assassinada. Transposição romanesca de uma história autêntica, a epopeia trágica e lamentável da fundação, em 1893, da cidade mineira de Pirapora por Joaquim Lúcio Cardoso, pai de Lúcio Cardoso, o romance de 1934 apresenta fundamentos históricos e se inscreve na marcha pioneira da conquista territorial do Brasil. 
A narrativa traz algumas das principais obsessões do autor, isto é, a presença do demônio e a convivência com o pecado e a morte, que, inegavelmente, estão presentes na Crônica da casa assassinada. A presença do demônio, revelada na Crônica da casa assassinada pelas confissões de Ana e pelas cartas de Padre Justino, além de marcar a obra de estreia e a Crônica, também está presente em $A$ luz no subsolo, romance marcado pelo clima fantasmagórico, de pesadelo e de opressão que, tendo sido apontado por Mário Carelli (1988) como a prefiguração mais clara da Crônica, também traz as paixões, a dualidade dos seres, a loucura, o ódio, a presença de uma casa também em decadência, infernal e o jardim, como lugar das transgressões, características que antecipam muitos aspectos composicionais da Crônica da casa assassinada. Em Salgueiro, romance de realismo social, porém, de dimensão simbólica que ultrapassa os limites da observação, Lúcio Cardoso não se contenta em descrever a condição humana, logo, sonda os corações, e mais ainda, as almas dos seres que, esmagados pela miséria, vivem um verdadeiro inferno, no morro do Rio de Janeiro, Salgueiro. Esse interesse de Lúcio pelas verdades ocultas por trás das máscaras que ele tenta despojar é representado na Crônica através da profundidade psicológica da apresentação dos personagens que são construídos no romance por eles mesmos e pelos outros pontos de vistas narrativos, pelos quais temos conhecimento dos fatos e assim podemos construir a história (CARELLI, 1988). Dias perdidos e $O$ viajante, publicado postumamente, em1973, são os romances que menos corroboram para a evolução apontada por Mário Carelli (1988). O primeiro é o romance que, segundo o autor supracitado, mergulha no esquecimento, talvez por seu caráter realista, linear, sem obscuridade, ou seja, diferente de todos os outros romances de Lúcio, que costumam conceber o real transfigurado pelas paixões, pelo ódio, pela loucura, entre outros temas frequentes nos escritos romanescos de Lúcio Cardoso. Ou seja, Dias perdidos, além de não trazer inovações não contribui, de forma visível, para a criação da Crônica da Casa assassinada, como os outros romances citados. $O$ viajante, posterior à Crônica, ao contrário dos romances antecedentes, retorna ao romance de 1959. Assim, voltando ao espaço fíctício de Vila Velha, Donana de Lara reaparece para viver a mulher que descobre a necessidade imperiosa de viver, pronta a sacrificar tudo para realizar seus desejos, marcando o romance pela visão "romântica" das paixões humanas. Não podemos deixar de relacionar essas paixões com as paixões que consomem e guiam as ações dos personagens da Crônica (CARELLI, 1988). Nesse contexto, podemos pensar a Crônica da casa assassinada através das características dos romances que o antecedem, de forma que esses romances venham a figurar, no conjunto da escrita romanesca cardosiana, como espaços de experimentação, laboratórios e embriões para a grande revolução que representa a Crônica da casa assassinada, como observa Carelli (1988) em seu estudo da vida e da obra do ficcionista de Crônica da assassinada, romance este que está para Lúcio Cardoso tal comoMemórias póstumas de Brás Cubas (1881) está para Machado de Assis (1839-1908) ou Grande Sertão: veredas(1956) para Guimarães Rosa (1908-1967).

\section{Da Crônica ${ }^{1}$}

Certamente, Crônica da casa assassinada (1959), configura-se como a principal composição literária de Lúcio Cardoso, isso porque em vários aspectos a obra assume traços considerados inovadores, com um forte punhado crítico à literatura produzida por seus contemporâneos e a estrutura social que ainda valorizava o tradicionalismo patriarcal, sistema que, sem dúvida, encontrava-se em derradeiro declínio, uma vez que a nação aspirava ares de mudança, seja pela transformação econômica do país, que, gradativamente, assumia uma face urbanizada, seja pela ascensão da mulher, que, ainda "submissa", começa a lutar por mais direitos sociais. A crônica apresenta-nos um leque de possibilidades para a leitura do processo composicional proposto por Lúcio Cardoso, uma delas, evidentemente, gira em torno do elevado grau de representatividade

\footnotetext{
${ }^{1}$ Gostaríamos de pontuar que a referência utilizada para corroboram as ideias deste ponto do artigo fora retirada do autor Mário Carelli, do seu livro Corsel de fogo, do ano de 1988.
}

da obra - personagens, espaços e objetos carregam sobre si diferentes significados - que são fundamentais para que se compreenda o andamento e o desfecho da narrativa. Já no título do romance percebe-se que "CASA está no sentido de família, de brasão. ASSASSINADA quer dizer, atingida na sua pretensa dignidade, pelo pecado." (Cf. Walmir Ayala, "Lúcio Cardoso e a casa assassinada" Jornal do Brasil, 7 de abril de 1963). Ou seja, o objetivo da narrativa não implica em desvendar um assassinato que possa ter acontecido na casa dos Meneses - tal como ocorre nos romances policiais - mas em retratar a decadência de toda uma família, símbolo do tradicionalismo patriarcal na cidade fictícia de Vila Velha. Esse declínio configura-se, sobretudo, devido ao pecado incestuoso entre Nina e seu suposto filho André, numa relação carregada de grande simbologia, que interfere diretamente nos acontecimentos posteriores na casa. Os espaços também não ficam atrás, todos parecem determinar os principais acontecimentos do enredo, uma vez que considerando as ocorrências dentro de um conjunto podemos perceber certa similaridade entre alguns fatos que coincidentemente ocorrem nos mesmos lugares, e acabam definindo, de certa maneira, o vinculo da casa com os personagens, nessa perspectiva: a casa seria o centro; o jardim, o espaço da transgressão; o pavilhão, o espaço que desempenha um papel alternativo aos personagens; a chácara, o lugar de aprisionamento dos personagens; Vila Velha, lugar que representa a hegemonia e manutenção dos valores legendários tradicionalistas patriarcais dos Meneses; e o Rio de Janeiro, a capital, o paraíso ilusório do romance.

$\mathrm{Na}$ construção cardosiana percebe-se que estes espaços apresentados acima desempenham essas funções repetidas vezes. No caso do jardim, por exemplo, que pode ser visto como o espaço da transgressão, é onde teremos o início de todas as relações "proibidas" da trama, é onde Alberto começará sua relação com Nina e Ana, e André dará os primeiros sinais de que está apaixonado por sua"mãe". Também, no tocante a representatividade da obra há grande semelhança ao que ocorre com três personagens - Nina, Ana e Timóteo - e o trágico desfecho da casa dos Meneses. Curiosamente são as três personagens mais femininas da trama, que em momentos distintos da narrativa, entram num profundo estado de degradação física e moral. Timóteo entrega-se ao alcoolismo; Nina degrada-se lentamente devido ao desgaste ocasionado pelos constantes conflitos na casa; e Ana ao ver que seu objeto de repulsa e admiração (Nina) acaba por sucumbir, também se entrega a doença, chegando até a sua derradeira morte. "A agonia e a morte de Nina significam o fim da Casa, que só será definitivamente assassinada com a morte de Ana. As duas mortes são lentas, ligadas a decomposição e associadas à degradação física e moral da Chácara." (CARELLI, 1988, p. 212). Ou seja, há, de fato, uma ligação direta entre a Casa e as personagens femininas do romance, o fim da Casa, ao qual nos referimos, diz respeito a total degradação da família, sobretudo, após a morte de Nina. Os Meneses desintegram-se totalmente, em suma por conta dos constantes atos pecaminosos que cercam os arredores da chácara.

Outro importante aspecto a ser mencionado acerca da construção composicional de Lúcio Cardoso, refere-se aos "múltiplos pontos de vista" do romance. Não há durante a narrativa plena concordância entre os vários narradores da Crônica. Quer dizer, uma afirmativa que é feita por um narrador acerca de um personagem pode discordar do que é dito por outro narrador durante o romance. É relevante notarmos que esta característica configura-se pela multiplicidade de narradores, que se revezam a todo instante durante a narrativa. Essa "discordância" fica evidente ao considerarmos as afirmações referentes ao coronel, nas narrativas de Valdo e Nina, como podemos observar, respectivamente:

"Então o militar, decidindo-se, um brilho de audácia no olhar: "Pois bem, podíamos ser amigos, podíamos ser até parentes!"(...) "Há aqui uma moça bonita, em idade de se casar." (...) "E o senhor pretende que eu jogue minha própria filha?" (...) "Não é a sua filha que o senhor joga , é a felicidade dela. (...) Moça nesta idade não tem direito de querer coisa nenhuma, tem é de fazer a vontade do pai." (CARDOSO, 1959, p. 89) 
Neste trecho percebemos um Coronel sádico e interesseiro, que não mede esforços para alcançar seus objetivos, evidentemente esta visão é passada ao leitor através da narrativa de Valdo, numa conversa com seu amigo farmacêutico, por esse motivo, é provável, que a antipatia e o ciúme dele para com o coronel tenham influenciado na construção do caráter de seu "adversário". Uma vez que Nina apresenta-nos um "outro" coronel:

"Ah, creio que teria sucumbido se não fosse a sua generosidade. Lembro-me em particular daquela noite em que fomos ao Cassino, e em que eu ganhei uma soma importante, fato decisivo, já que me achava definitivamente disposta a morrer (...) $\mathrm{O}$ senhor me animou em minhas intenções e, rompendo o silêncio de anos, escrevi ao meu marido (...)" (CARDOSO, 1959, p. 188)

Na visão da heroína da Crônica o coronel, agora, é apresentado com considerável generosidade, o único capaz de estender a mão à Nina no momento mais difícil de sua vida, quando esta se encontrava abandonada pelo marido, sem qualquer tipo de auxílio afetivo e financeiro. Dessa maneira, é evidente que "Lúcio explora a riqueza da polifonia em suas possibilidades extremas - um mesmo personagem visto em dois momentos distintos por protagonistas diferentes não tem necessidade de ser verossímil como um todo; essas visões opostas coexistem nas consciências." (CARELLI, 1988, p. 189).

Lúcio cardoso, o cinema e as adaptações: Segundo Mario Carelli (1988), é evidente o parentesco entre o romance cardosiano e o cinema, vários filmes já foram feitos baseados em sua obra. Além disso, a paixão de Lúcio Cardoso pelo cinema é uma relação que pode ser remontada desde sua infância, e de maneira tão forte que sua irmã, Maria Helena Cardoso, não deixará de registrar em seu livro de memórias, Por onde andou meu coração, do qual temos registro em Corcel de fogo:

Apesar de garoto e eu, moça de dezenove para vinte anos, nos dávamos muito bem. Como gostava de ler, tomei a peito orientálo, tendo começado com livros de Dickens, Crime e Castigo, Recordação da casa dos mortos, de Dostoiévski, de mistura com os romances de folhetim, que seguíamos ansiosos. Tinha paixão pelo cinema, conhecendo toda a sua história, acompanhando os grandes filmes, que se lançavam na época. Apesar com onze para doze anos, já falava sobre Cecil B. de Mille e filmes como O gavião do mar, atrizes como Alma Rubens, Ala Nazimova. Insistia para que fôssemos ver um determinado filme que sabia ser muito bom, por ter seguido a filmagem através das revistas de cinema, estando a par da vida dos intérpretes, do diretor, dos vários incidentes por ocasião da filmagem (...) Sentava-se à nossa frente e durante os intervalos voltava para nós o rosto ansioso, os olhos inquietos e brilhantes, como a indagar a nossa impressão (...) Foi o primeiro a me falar de Greta Garbo que acabava de aparecer no filme Laranjais em flor. A instâncias suas, fomos juntos ao cinema Odeon, vê-la em $A$ carne e $O$ diabo. Saiu de lá no maior entusiasmo (...) O dia todo passávamos conversando do seu mundo: o cinema, os livros que líamos, os dramas da vizinhança.” (CARDOSO, 1968, p. 265266 apud CARELLI, 1988, p. 24).

De espectador apaixonado, Lúcio passará a produtor, roteirista, diretor e ator em várias produções cinematográficas baseadas em romances seus. Destacamos, entretanto, as parcerias com Paulo Cesar Saraceni em Porto das Caixas (1961), O Enfeitiçado (1968) e A Casa Assassinada (1971), que baseados, como já dito, em romances de Lúcio Cardoso, também dão espaço para que ele participe como ator. Pensemos, portanto, em particular, e, sobretudo, no filme que Paulo Cesar Saraceni fez a partir de Crônica da casa assassinada (1959), "o romance incontestavelmente mais "cinematográfico"” (CARELLI, 1959 , p. 87). Na adaptação cinematográfica, o enredo se dá da seguinte forma: após casar com Valdo (Rubens Araújo), Nina (Norma Bengell), mulher atraente e de modos liberais, sai do Rio de Janeiro para morar na provinciana chácara dos Meneses, em Vila
Velha, no interior de Minas Gerais, família que decadente não possui sequer rendas para mantê-la. Nina enreda-se na complexa teia familiar que envolve a hostilidade do irmão mais velho de Valdo, Demétrio (Nelson Dantas), sua reprimida mulher Ana (Tetê Medina), o delírio do irmão, homossexual rejeitado, Timóteo (Carlos Kroeber). Soma-se a isso o desejo de Nina pelo jardineiro da casa, Alberto (Augusto Lourenço). Os boatos de seu envolvimento com o jardineiro acabam provocando uma tentativa frustrada de suicídio do marido, o jardineiro, no entanto, é quem se suicida. Nina parte para o Rio de Janeiro, retornando 17 anos depois. Quando de seu retorno, se envolve numa possível relação incestuosa com o suposto filho, André (Augusto Lourenço). Acometida por um câncer, Nina vem a falecer, finalmente, Ana revela ao padre local que, no entanto, André era fruto de sua relação extraconjugal com o jardineiro. O enredo de A casa assassinada é semelhante ao enredo do romance de Lúcio Cardoso. A diferença se concentra no apagamento dos múltiplos pontos de vista, técnica narrativa que possibilita ao leitor reconstruir a história. Entretanto, o filme adapta a obra literária sem comprometer a história central, apenas adaptando-o a uma nova linguagem artística.

\section{FREUD E O CONTINENTE NEGRO: a feminilidade em pauta.}

Nesta parte do artigo, iremos abordar de que maneira a feminilidade tem destaque em Freud e na psicanálise freudiana, de que maneira houve essa articulação. Para isso, buscamos elucidações de cunho histórico-conceituais em Peter Gay, historiador, psicanalista e biógrafo de Freud, quem dedicou uma parte do seu livro (Freud: uma vida para o nosso tempo) para nos apresentar essa relação entre o feminino e a psicanálise, ou entre o feminino e o Freud. Para que, em seguida, possamos entender o texto que Freud dedicou completamente à teoria da feminilidade, pois o mesmo vem a contemplar um momento decisivo na psicanálise freudiana, onde Freud dedica uma conferência inteira para tentar apontar os aspectos que considera de suma valia para o entendimento da feminilidade, mesmo que seus escritos anteriores tenham dado indícios, tenha sido enfático, tendo feito diversas postulações acerca da feminilidade. A psicanálise aponta Gay (2012), tem o seu início marcado com o enigma que o feminino evoca, ou seja, o que está nas entrelinhas da subjetividade, o que não está manifesto, o que está por trás de um sintoma que um sujeito apresenta, é enigmático e é este ponto específico que interessa e sempre interessou à psicanálise. Numa época em que mulheres eram consideradas passivas, frigidas, sem desejo, Freud percebeu que elas tinham um saber a ser escutado e que ninguém se importava, eis então que ele deu voz a elas. Muitos teóricos, inclusive, afirmam que foram as histéricas quem criaram a psicanálise e não Freud (aqui em tom chistoso, é claro).

A psicanálise, ao longo de toda a sua construção faz articulações acerca da sexualidade feminina, acerca da feminilidade e acerca do feminino, contudo, Freud, em 1928, numa conversa com seu contemporâneo e amigo Ernest Jones ${ }^{2}$, afirma que tudo o que se sabia até aquele ponto sobre o desenvolvimento inicial feminino parecia insatisfatório e dúbio (GAY, 2012). Mas fora somente, ainda segundo Gay (2012), numa carta à outra amiga - Marie Bonaparte - que Freud consternado sobre suas publicações, seus atendimentos ${ }^{3}$, afirma que pesquisa sobre a alma feminina há mais de trinta anos, entretanto somente havia obtido resultados espessos, parcos, e imerso a isso, ele faz a famosa indagação: o que quer uma mulher? (que, posteriormente tornou-se jargão psicanalítico universal - inspirou filmes, séries, livros, etc.). E já que citamos anteriormente Ernest Jones, vamos retomá-lo, tendo em vista que ele e Karen Horney foram dois psicanalistas que muito criticaram algumas postulações freudianas no que tange a sexualidade feminina. Karen, principalmente, ela não tolerava o fato de Freud afirmar que a feminilidade era adquirida com a então renúncia de traços masculinos. Karen e Jones acreditavam que Freud ao definir o clitóris

\footnotetext{
${ }^{2}$ Quem mais tarde tornara-se seu biógrafo.

${ }^{3}$ Um, especificamente, o famoso caso Dora. Freud estava atendendo Dora e imerso aquele caso que tanto o demandava, escreve à Bonaparte e faz a famosa indagação: "O que quer a mulher?".
} 
como um pênis residual, estava laçando-se com tendenciosidade à esta temática:

\section{Os criticos tinham razão. Em 1922, Horney levantou-se corajosamente no congresso internacional de psicanalistas em Berlim, com Freud na presidência da mesa, e sugeriu uma versão revista da inveja do pênis. Ela não negava sua existência, mas situou-a num contexto de desenvolvimento feminino normal. A inveja do pênis não gera a feminilidade, disse Horney, mas, pelo contrário, é uma expressão sua. Por isso ela rejeitava a ideia de que essa inveja leva necessariamente as mulheres ao "repúdio de sua natureza feminina". Muito pelo contrário, "podemos ver que a inveja do pênis não impede de forma alguma uma ligação amorosa e profunda e inteiramente feminina com o pai" (GAY, 2012, p. 522).}

Horney apontou algo que é de suma importância para o entendimento da sexualidade feminina e da feminilidade propriamente dita, que era uma revisão na teoria da inveja do pênis que Freud havia teorizado, mas este não era o único conceito que merece atenção quando falamos em feminilidade, é necessário entender conceitos como complexo de Édipo, complexo de castração, ou até mesmo entender a ligação pré-edipiana da menina com a mãe, entre outros aspectos.

\section{Cinema e Psicanálise}

Freud, desde os primórdios da criação da teoria psicanalítica, utilizase de produções artísticas para dar forma às suas criações, fazendo com que a teoria ganha um contorno outro que somente a teoria proporcionaria. Desta forma, com a análise dos sonhos, Freud simplesmente transformou as imagens em palavras, assim como faz o psicanalista que, ao analisar um filme, transforma as imagens em compreensão teórica sobre o inconsciente:

"Não é à toa que o cinema se interessa por vezes pela psicanálise (em geral, de maneira caricata). E também não é à toa que a psicanálise pode se interessar pelo cinema. À psicanálise interessa esse mesmo ponto agudo da constituição, da dor e da fruição do sujeito. A psicanálise nasce entrelaçada à arte, com a tragédia Édipo rei, de Sófocles, seguida de Hamlet, de Shakespeare" (RIVERA, 2008, p. 9).

Derrida, em entrevista ${ }^{4}$ a Antoine de Bacque, em 2001, afirma que a psicanálise ou até mesmo para sermos mais específicos, a leitura psicanalítica encontra-se diretamente à vontade no mundo cinematográfico. Diversos fenômenos ligados à projeção, ao espetáculo, à percepção desse espetáculo, possuem equivalentes psicanalíticos. Walter Benjamin ligeiramente se apercebeu deste fenômeno e realizou aproximações na análise cinematográfica da psicanalítica. Inclusive a visão e a percepção do detalhe num filme estão em relação direta com o procedimento psicanalítico. A psicanalista Renata Cromberg, ao proferir algumas palavras introdutórias no prefácio do livro do psicanalista Sérgio Telles, intitulado $O$ psicanalista vai ao cinema, afirma que existem diversos meios ou movimentos de aproximações viáveis entre o cinema e a teoria psicanalítica, de maneira mais focal, eles podem ser divididos em três partes. Na primeira parte, o filme seria o depositário de pretexto para a reflexão psicanalítica, como uma espécie de descrição minuciosa e imagética da narrativa de casos clínicos, sendo assim, os personagens e suas respectivas tramas são analisados como se configuram casos clínicos do psicanalista. Já no segundo momento, a película serve como pretexto para a reflexão psicanalítica, entretanto, a trama e os personagens, aqui, ficam de lado, o que é levado em consideração são as questões mais amplas que eles trazem para a área psicanalítica em seu bojo conceitual. E finalmente, na terceira parte, o cinema serve ao psicanalista como forma de criação de imagens e de pensamento por imagens. Trata-se de pensar uma vida em

\footnotetext{
${ }^{4}$ Esta entrevista fora apresentada na folha de introdução do livro de Sérgio Telles - o psicanalista vai ao cinema, de 2004.
}

movimento, que pede para ser escutada com o olho e vista com o ouvido (CROMBERG, 2004, p. 14).

Um ponto a nos atentarmos quando nos referimos a esta relação entre cinema e psicanálise, é lembrar que não procuramos fazer desta relação uma espécie de ancoramento entre arte e teoria, no sentido de tentar abarcar a arte na teorização, isto seria um erro. Com isso, quando referimos aqui acerca da utilização de obras cinematográficas, e não a análise nua e crua da mesma, é por lembrarmo-nos do que Freud nos alerta no seu texto $O$ Estranho, de 1919. O Autor afirma que aqueles que cogitarem a possibilidade de analisar a arte terão uma má surpresa e aquilo que pretendiam executar ficará no mínimo confuso, tendo em vista que - na literatura, por exemplo - é impossível adequar a escrita de um artista aos construtos teóricos, almejando encontrar uma única verdade ali embutida. Na verdade, existe uma multiplicidade de existências que a escrita é capaz de nos proporcionar. O mesmo vale para o cinema.

\begin{abstract}
"Não se trata de aplicar a psicanálise às obras para apontar nelas alguma verdade que apenas esta disciplina poderia revelar. Ao contrário, trata-se de buscar conhecimento sobre o homem nessas obras e, mais especificamente, com elas aprender sobre o sujeito e sua relação com a imagem" (RIVERA, 2008, p. 9-10).
\end{abstract}

Bartucci (2000) afirma que tendo em vista que o cinema está completamente atrelado com o desejo, com o imaginário, com o simbólico, já que utiliza de jogos de identificação e de mecanismo que regulam nosso inconsciente e nosso psiquismo, ele (cinema) estabelece, dessa maneira, uma relação ímpar com a psicanálise. Assim como também é verdade que a psicanálise encontra no cinema um interlocutor profícuo. A ideia, aqui neste ponto da discussão do artigo, é mostrar de que maneira cinema e psicanálise conversam e como essa relação é posta em atividade. Sendo assim, vimos que as possibilidades se unem nas semelhanças. Cinema e Psicanálise tem um ponto de interlocução, também, a partir da criação do campo em que o cinema entrega ao espectador à potência da imagem, fazendo com que a atenção fique fixada num domínio imaginário, como aponta Sampaio (2000), há uma produção de mistura dosada de passividade, fascinação, sideração e curiosidade. No mais, podemos resumir que, como afirma Rivera (2008) nenhuma análise, psicanalítica ou não, pode ser capaz de parar a imagem, com isso, ela deve se dar por satisfeita em acompanhar suas errâncias ou duplicar sua fixidez. Mesmo porque, uma teoria de base psicanalítica é sempre incompleta e parcial ou em outros termos pulsante, pois o que está em jogo é o sabor efêmero e imprevisível efeito de sujeito.

FEMINILIDADE EM A CASA ASSASSINADA: uma leitura psicanalítica da feminilidade no filme de Paulo César Saraceni.

Em nosso artigo, optamos por realizar uma análise mais focal da obra de Saraceni a casa assassinada, à luz da teoria psicanalítica. Para que assim, possamos entender determinados aspectos da teoria da feminilidade em nosso personagem central - Nina - e fazer, com isso, que um maior entendimento se personifique nesse estudo. Desta forma, optamos por utilizar o texto central de Freud sobre esta temática, que é a conferência XXXIII, intitulada Feminilidade. Esta conferência é baseada em dois escritos anteriores de Freud, um que fora intitulado de algumas consequências psíquicas da distinção anatômica entre os sexos, datado em 1925 e outro nomeado de sexualidade feminina, do ano de 1931 . Pois bem, enquanto o primeiro aborda as consequências psíquicas da diferença anatômica, ou seja, quais os resquícios que o confrontamento da descoberta dos órgãos masculinos e femininos causa nas crianças a nível psíquico. Já o outro, devido ao vasto material clínico de Freud, aborda a intensidade e longa duração da ligação pré-edipiana da menina à mãe, entretanto, o mais interessante aqui seja o fato que Freud realiza um extenso exame da questão do ativo na atitude da menina para com a mãe e na feminilidade em $\mathrm{si}^{5}$. Ao longo do texto, usaremos fragmentos e

${ }^{5}$ Informações retiradas da nota do editor inglês (James Strachey) das obras completas de Freud, encontradas nos textos sexualidade feminina, de 1931 e feminilidade, de 1933. 
voltaremos ao texto original para fomentar a discussão aqui proposta. Sabe-se que o filme de Saraceni a casa assassinada é baseado no romance mais conhecido do autor Lúcio Cardoso, crônica da casa assassinada. Saraceni realizou uma adaptação da obra de Cardoso para o cinema, entretanto, permaneceu bastante fiel à obra de Lúcio Cardoso, encarnando no filme até mesmo falas e situações idênticas às quais ocorrem no livro. Já que sabemos que o filme é baseado no livro, e que ambos são e que a adaptação é bastante fiel à obra literária, vamos entender alguns aspectos centrais que nos auxiliarão a entender o papel do feminino no livro e concomitantemente no filme.

A presença de personagens femininas em Lúcio Cardoso é constante e de suma importância, inclusive, Nina de crônica da casa assassinada, é a personagem feminina mais estudada de Lúcio Cardoso, em diversas áreas do conhecimento. A figura da mulher encarna e constitui base de seu fazer artístico, como se ela fosse, ao mesmo tempo, o enigma e a resposta. Enigma este tão falado por Freud e psicanalistas pós-freudianos (CARDOSO, 2010). Cardoso (2010) afirma que a própria definição da feminilidade, nos permite entender que ela atua nos arranjos dos acontecimentos, justamente pela sua indefinição (do feminino) é que isto ocorre e também se vincula na multiplicidade. Multiplicidade esta que é a chave mestra para entendermos tanto o feminino quanto as personagens femininas de crônica da casa assassinada. Se fosse imposto a nós que definíssemos em apenas uma palavra a feminilidade, esta seria múltipla. Não há, com isso, um único modo de ser mulher, mas vários e já adentrando um pouco o filme de Saraceni, vemos isso no modo com as personagens são postas em cena, Nina e Ana são diferentes, mas é justamente nessas diferenças que elas se completam. Nina e Ana apesar de diferirem em termos subjetivos, elas nos mostram como cada uma encontrou uma maneira para expressar sua condição enquanto mulher. Um dado importante da relação de Nina e Ana é fato de que Ana nutria por Nina uma forte paixão (encoberta inferência dos autores) e isto acontece pelo fato de Nina despertar em Ana novas possibilidades de expressar a feminilidade. Ana, diante de Nina, descobre possibilidades femininas das mais corriqueiras, como a vaidade de um penteado, até das mais polêmicas, como o direito reprodutivo, estabelecendo uma relação paradoxal de repulsa e adoração com a cunhada (CARDOSO, 2010).

Ao analisar este dado por outro ponto de vista, buscamos em Joel Dor, uma possível elucidação do sentimento de Ana por Nina. E eis então que através da teoria da identificação histérica, podemos ter novas possibilidades de compressão teórica:

Uma mulher histérica pode identificar-se com facilidade a uma outra mulher se esta última supostamente conhece a resposta ao enigma do desejo: como desejar quando se está privado daquilo a que se tem direito? A partir do momento em que uma mulher desejante se apresenta como "não o tendo" mas desejando-o apesar de tudo junto àquele que é suposto tê-lo, esta mulher aparece de imediato, para o histérico, como aquela que lhe trará a solução para a sua questão (DOR, 1997, p. 69).

Aqui, vemos que a questão que está posta é que Ana identifica-se inconscientemente com Nina porque Nina para deter a resposta para o seu enigma do desejo, é como se Nina pudesse responder a famosa indagação $O$ que quer uma mulher?.E como estamos em âmbitos inconscientes, quando Nina faz a pergunta à Ana $O$ que você não daria para ter os cabelos iguais aos meus?, podemos entender que, na verdade, ela estava perguntando $O$ que você não daria para possuir tudo isso que eи possuo?.

A importância da beleza na personagem Nina é algo perceptível, mas o interessante de apreender é que não se trata da questão física, mas sim, a psíquica. Por que Nina tenta, a todo instante, exaltar seus atributos físicos? Porque eles são depositários de seu conflito psíquico. Zalcberg (2003) mostra que nos encantos da feminilidade as mulheres acham, de certa maneira, uma solução para lidar com a sua condição indefinida enquanto mulher. É talvez por isso que, ao exaltar os encantos do seu corpo feminino, a mulher cria uma possível feminilidade.
Em Freud (1933) vemos isso da seguinte maneira:

A inveja do pênis tem em parte, como efeito, também a vaidade fisica das mulheres, de vez que elas não podem fugir à necessidade de valorizar seus encantos, do modo mais evidente, como uma tardia compensação por sua inferioridade sexual original. A vergonha, considerada uma característica feminina par excellence, contudo, mais do que se poderia supor, sendo uma questão de convenção, tem, assim acreditamos, como finalidade a ocultação da deficiência genital (p.131).

Na conferência XXXIII - Feminilidade, Freud (1933) afirma que à feminilidade atribui-se maior quantidade de narcisismo, o que faz com que a escolha objetal da mulher seja afetada, sendo assim, podemos entender por que pra Nina existe uma necessidade bem maior de ser amada do que de amar. É uma necessidade inerente à feminilidade e a sua expressão se dá nas relações que ela estabelece com os objetos.

\section{CONSIDERAÇÕES FINAIS}

Na obra literária de Lúcio Cardoso, percebemos ser possível estabelecer diferentes conexões com outras áreas de conhecimento e da arte, como a psicanálise e o cinema. Por isso, constatamos que esta interlocução se deu de maneira satisfatória, pois, mesmo não sendo a psicanálise o foco principal de Lúcio Cardoso, ela serve como uma possibilidade de leitura e articulação de sua obra, em especial, Crônica da casa assassinada. Concluímos, dessa maneira, que a construção composicional da Crônica é, sem dúvida, a obra-prima do escritor mineiro. E, acreditamos que a feminilidade é uma problemática central no romance, como fora exposto ao longo do artigo. $\mathrm{O}$ artigo não tivera o intuito de encerrar discussões acerca da feminilidade freudiana em Lúcio Cardoso, entretanto, nos propusemos a abrir um espaço de múltiplas discussões relativas à esta temática, para que futuramente, possamos dialogar com outras formas de pensamento e outras áreas de conhecimento, como a literatura e a arte.

\section{REFERÊNCIAS}

BARTUCCI, Giovanna. Psicanálise e estéticas de subjetivação. In: BARTUCCI, G. (org). Psicanálise, cinema e estéticas de subjetivação. Rio de Janeiro: Imago, 2000.

CARDOSO, Elizabeth da Penha. Feminilidade e Transgressão - uma leitura da prosa de Lúcio Cardoso. São Paulo (USP), 2010. Tese de Doutorado em Letras.

CARDOSO, Lúcio. Crônica da casa assassinada. Rio de Janeiro: José Olympio, 1959.

CARRELI, Mario. Corcel de fogo. Tradução de Júlio Castañon Guimarães. Rio de Janeiro: Editora Guanabara, 1988.

CROMBERG, Renata U. Prefácio. In: TELLES, S. O psicanalista vai ao cinema. São Paulo: Casa do Psicólogo; São Paulo: EdUFSCar, 2004

DOR, Joel. Estruturas e clínica psicanalítica. Rio de Janeiro: Taurus, 1997.

FREUD, Sigmund. Edição Standard Brasileira das Obras Completas - ESB. Tradução de Jayme Salomão. Rio de janeiro: Imago, 1974.

(1919). O Estranho. In: ESB. Op. Cit. XVIII.

(1933). Feminilidade. In: ESB. Op. Cit. V. XXII.

GAY, Peter. Freud: uma vida para o nosso tempo. Tradução de Denise Bottmann. São Paulo: Companhia das Letras, 2012.

RIVERA, Tânia. Cinema, imagem e Psicanálise. Rio de Janeiro: Jorge Zahar, 2008.

ZALCBERG, Malvine. A relação mãe e filha. Rio de Janeiro: Elsevier, 2003.

SAMPAIO, Camila Pedral. O cinema e a potência do imaginário. In: BARTUCCI, G. (org). Psicanálise, cinema e estéticas de subjetivação. Rio de Janeiro: Imago, 2000. 